\title{
Teachers' perspectives on educator mental health competencies: A qualitative case study
}

\author{
Diane Kratt \\ Florida Gulf Coast University, USA
}

\begin{abstract}
Given the prevalence of children's mental health disorders, teachers' roles have expanded to include identifying students with mental health needs and delivering mental health interventions. However, teachers rarely receive mental health training. This study's purpose was to explore teachers' perspectives on an educator mental health competency framework proposed by a group of researchers using the following questions: (a) how the competencies could guide and inform their practice; $(b)$ how the teachers would react if the competencies were adopted; and $(c)$ what suggestions they had for improving the competencies. The participants' responses indicated that they needed more knowledge on mental health and larger systems of support to increase their classroom effectiveness. Overall, the teachers supported the adoption of the competencies but had reservations regarding the necessary training and implementation process. Although the participants did not provide direct suggestions on revisions to the competencies, they did imply suggestions. Findings support the use of the mental health curriculum framework in the development of teacher mental health training. Several implications for practice are proposed including the addition of mental health curriculum in teacher preparation programs and the necessity for school administrators to create a school culture and infrastructure to effectively support school mental health.
\end{abstract}

KEYWORDS: school mental health, educator competencies, teacher preparation, professional development, social emotional development

\section{Teachers' Perspectives on Educator Mental Health Competencies}

Although the media gives visibility to mental-health-related tragedies, the reality is that the United States children's mental-health crisis is largely invisible and silent. Between 14-20\% of children and adolescents experience a mental, emotional, or behavioral disorder each year (Adelman \& Taylor, 2010; National Research Council and Institute of Medicine, 2009; World Health Organization, 2003). With millions of children and adolescents in the United States experiencing a mental, emotional, or behavioral disorder each year (National Center for Education Statistics, 2014), the impact on student school success is significant (Adelman \& Taylor, 2010; 
O’Connell, Boat, \& Warner, 2009; Paternite \& Johnson, 2005; Waxman, Weist, \& Benson, 1999; Weist \& Evans, 2005).

School personnel are the most common providers of service to children and youth who have mental-health disorders. National policies and briefs, such as the New Freedom Commission on Mental Health Report (2003), identified schools as a natural setting and best site to provide mental-health treatment and prevention services to youth (Adelman \& Taylor, 2010; Cammack, Brandt, Slade, Lever, \& Stephan, 2014). In schools, mental-health services are typically delivered by school mental-health (SMH) professionals, including the school counselor, psychologist, nurse, and social worker. However, schools do not have appropriate resources for addressing emotional and behavioral challenges and the ratios of SMH professionals fail to meet the demand for effective comprehensive services (Weist, Lever, Bradshaw, \& Owens, 2014). Furthermore, the SMH professionals often lack time to focus on preventing and addressing emotional and behavioral challenges (Waxman et al., 1999; Weist et al., 2014). To mitigate this situation, the expanded school mental-health (ESMH) model not only includes the use of school and community-based, mental-health professionals, but also the use of educators to address the mental-health needs of the students. However, this expansion in $\mathrm{SMH}$ leads us to examine further the role of the teacher regarding children's mental health and determine his or her level of preparedness for the task.

Through their day-to-day interactions with students, teachers play a pivotal role, not only in the academic needs, but also in the overall social and emotional development of youth (Anderson-Butcher, 2006; Paternite \& Johnston, 2005; Weyns et al., 2017; Yigit \& Tatch, 2017). However, a teacher's specific role in ESMH is relatively new and research in this area is still in its infancy. Researchers have examined teachers' perspectives on the mental-health needs of students and the extent of teacher preparation for this role (Deniz \& Ersoy, 2015; Ersoy, 2015). Overwhelmingly, teachers lacked specific knowledge on mental health, and there was a need for effective teacher training to garner greater knowledge and skills regarding mental health (Bishop, Giles, \& Bryant, 2005; Franklin, Kim, Ryan, Kelly, \& Montgomery, 2012; Graham, Phelps, Maddison, \& Fitzgerald, 2011; Mazzer \& Rickwood, 2014; Halpern, 2017; Williams, Horvath, Wei, Van Dorn, \& Jonson-Reid, 2007).

The United States is not alone in the need to address mental-health concerns of its students. There is an alarming increase in prevalence rates and an increased need to provide mental-health support in Canadian schools (Climie, 2015). Adolescent mental health has significant implications on students and schools (Meldrum, Venn, \& Kutcher, 2009; Volk, Craig, Boyce, \& King, 2006). Specifically, mental-health disorders represented the most common disabling condition, which affected young people (Carothers \& Parfitt, 2017; Meldrum et al., 2009). In addition, researchers in Australia identified 14\% of students as having mental-health problems (Sawyer et al., 2001). In a study that reviewed mental-health services in Australia, Ireland, and the UK, it was reported that access to mental-health services was the poorest for children and youth (McGorry, Bates, \& Birchwood, 2013). As was indicated in the results of these studies, there is a global need to identify and support students with mental-health disorders.

\section{Review of Literature}

Teachers play an integral role in identifying students who have mental-health issues, referring students to the appropriate mental-health professionals, and providing appropriate interventions. Teachers are often the first professional to encounter symptoms of a child or youth in need of mental-health services (Lafee, 2013; Paternite \& Johnston, 2005). Additionally, they 
are central figures in the identification process due to the constant monitoring of students' academic, social, and emotional needs (Anderson-Butcher, 2006; Arslan \& Yigit, 2016). Once identified, teachers refer students to school-based, mental-health professionals. Collaborative partnerships between teachers and mental-health professionals are essential in the promotion of mental health and school success for children and adolescents (Elias, Zins, Graczyk, \& Weissberg, 2003; Nellis, 2012; Paternite \& Johnston, 2005). To increase student success, the use of the MultiTiered System of Support (MTSS) framework is an effective way for school personnel to provide interventions for students in various stages of mental-health need within the learning environment (Rossen \& Cowan, 2014; Weist et al., 2014). MTSS includes whole-school approaches such as Response to Intervention (RTI) and Positive Behavior Intervention Supports (PBIS). There are three tiers of interventions, and teachers are the primary agents for delivering tier one and two MTSS supports (Bradshaw, Bottiani, Osher, \& Sugai, 2014). Identification, referrals, and interventions all represent important teacher roles regarding mental health.

Given the significance of these roles, researchers sought teachers' perceptions related to mental-health knowledge and training. Recent findings indicated the need for effective teacher training to garner greater knowledge regarding mental health (Bishop, Giles, \& Bryant, 2005; Franklin et al., 2012; Graham et al., 2011; Williams et al., 2007). For example, through a needsassessment survey administered to 119 elementary school teachers regarding student mental-health problems, teachers reported they lacked knowledge and training, which lessened their ability to solve mental-health problems (Walter, Gouze, \& Lim, 2006). Similarly, researchers interviewed 32 teachers in England, and through the results of the study, documented the need for teacher training to recognize and address mental-health problems (Rothi, Leavey, \& Best, 2008). Moreover, a study in Canada suggested the need for a sustained, research-based focus on effective ways to promote mental-health literacy among teachers. Most Canadian teachers perceived mental-health issues as pressing concerns in their schools (Whitley, Smith, \& Vaillancourt, 2012). Overall, teachers from around the world lack knowledge and training on mental health, which can impact their ability to carry out those additional roles effectively.

As indicated in another research finding, due to the lack of time, teachers felt overwhelmed with taking on the role of a mental-health provider (Bishop et al., 2005; Graham et al., 2011; Williams et al., 2007), and often struggle with their own mental well-being (Schonert-Reichl, 2017). For instance, researchers who conducted a study involving K-12 teachers in Norway showed that teachers often saw and identified a mental-health problem, but did not have time to engage and provide the student special attention amidst the day-to-day responsibilities (Ekornes, 2017). Furthermore, when teachers encounter a student mental-health issue, they are often uncomfortable in this yet-undefined role. For example, in a comprehensive study in Australia, Graham et al. (2011) found that teachers were most comfortable dealing with familiar family situations such as divorce and moving. Moreover, most teachers in their study identified mentalhealth education as "very" or "extremely" important, and were willing to be involved in mentalhealth education programs outside of the usual classroom processes. Additionally, because of the lack of available resources, many of the teachers felt a sense of isolation when dealing with problems, which arose from children with mental-health conditions (Graham et al., 2011). Phillippo and Kelly (2014) also found high school teachers experienced little collaboration with SMH professionals. Their study led to a conclusion that the teachers were an underused resource for mental-health services; therefore, changes to the structure and practice were necessary to expand the schools' mental-health supports. 
Teachers have reported feeling incompetent and ill-prepared to assume a more active role in school mental-health initiatives. One contributing factor is lack of formal education on mental health for pre-service teachers (Mazzer \& Rickwood, 2014; Phillippo \& Kelly, 2014; Walter et al., 2006). To compound the problem, there is minimal in-service training available to teachers for addressing mental-health concerns in the classroom (Ersoy \& Deniz, 2016; Koller, Osterlind, Paris, \& Weston, 2004). When teachers enter the classroom untrained to deal with students with mental-health problems, they often become frustrated, disappointed, and discouraged (Koller et al., 2004). Therefore, developing effective and relevant teacher training in mental health is a recent challenge in ESMH. Although mental-health teacher training is a new initiative; school personnel in Australia and Canada have already begun to field test different approaches (Jorm, Kitchener, Sawyer, Scales, \& Cvetkovski, 2010; Whitley et al., 2012).

To assess and understand current mental-health training in the United States, researchers examined educational policies and teaching competencies in each state seeking evidence of mental-health curriculum (Weston, Anderson-Butcher, \& Burke, 2008). An absence of a comprehensive framework of mental-health competencies for teachers was found in all states. Weston et al. (2008) created and proposed an integrated, comprehensive mental-health competencies curriculum framework, which consisted of 34 specific dispositions and six major domains of knowledge and skills that were recommended for inclusion in pre-service and inservice professional preparation programs. The Weston et al. (2008) proposed six targeted competence domains included:

1. The teacher demonstrates understanding and application of key policies and laws that foster delivery of effective and ethical learning supports in schools.

2. The teacher demonstrates knowledge and skills related to the provision of learning supports that promote academic achievement, healthy development, and overall school success.

3. The teacher demonstrates knowledge and skills in the collection and use of data measuring student behaviors, affect, and attitudes, as they relate to academic, social, and emotional needs and outcomes.

4. The teacher possesses and demonstrates the skills to communicate effectively and build relationships with others.

5. The teacher engages multiple systems and people in practices that maximize students' academic achievement, healthy development, and overall school success.

6. The teacher demonstrates knowledge and skills that facilitate personal and professional growth, development, and overall well-being.

To date, it is the only comprehensive framework available for mental-health teacher preparation or professional development (Ball et al., 2016). However, in a recent comprehensive study, Ball et al. (2016), examined state standards from 48 states and the national Interstate Teacher Assessment and Support Consortium (InTASC) standards for evidence of the SMH competencies identified by Weston et al. (2008). As shown in the results, there was an increase since 2008 in the use of SMH competency language in the standards. Moreover, all the professional state-standard documents that were examined contained standards aligned with at least one of the six SMH competency domains. In addition, the InTAS standards contained content from all SMH competency domains. Overall, these standards documents reflected the increased importance of teachers' involvement in SMH. However, gaps existed, variability among the states was present, and the focus for most of the competencies was on academic domains, rather than social and emotional domains (Ball et al., 2016; Ersoy \& Ugur, 2015). Therefore, this study was framed using 
the proposed educator mental-health competencies from Weston et al. (2008) as a framework for teacher training curriculum.

\section{Research Questions}

The purpose of the study was to explore the participating teachers' perspectives regarding the content and implementation of the proposed mental-health competency framework with the following research questions.

1. What are the participants' perceptions regarding how mental health competencies can guide and inform their classroom practice?

2. How would the participants react if these competencies were adopted by the state?

3. In what ways would the participants amend, add, or change the proposed mental health competencies?

\section{Methodology}

\section{Research Design}

The qualitative research design used was an instrumental case study, which means it seeks to understand a specific issue or problem (Stake, 1995). Creswell (2013) stated that a good qualitative case study provides an in-depth understanding of the case where assertions are formed by the researcher about the overall meaning derived from the case and are reported at the end of a study.

Through the case study, which used focus-group interviews as the primary data source, I investigated teachers' opinions and ideas related to the issue of applying the proposed educator mental-health competencies to their practice. The case was bound by several factors, which included the fact that all participants were general-education teachers who worked in an elementary school setting within the same school district. For this study, the case was formed from teachers at three different elementary schools within the same school district. In this way, focusgroup interviews were conducted to explore and examine the proposed educator mental-health competencies.

\section{Participants}

Three elementary schools from a large school district in Southwest Florida provided the setting for this study. The school district uses a school-choice model for student assignment and is divided into three geographic zones: (a) west, (b) east, and (c) south. Three Title 1 elementary schools, one representative from each zone in the school district, were selected to recruit participants for the study. An email request was sent to all the general-education faculty at each elementary school seeking voluntary participation in the study. Initially, 11 teachers total from all three schools volunteered to participate in the study.

All 11 participants who volunteered for the study were female, and all were generaleducation teachers. In the west zone school, there were five teachers who began the study, but only four completed. One teacher completed the initial survey, but did not join the focus group. In the south and east zone schools, each school had three teachers participate. The grade levels represented by all the participants ranged from kindergarten through fifth. The only level with no teacher representative was first grade. Years of teaching experience ranged from one participant being in her first year of teaching to three having over 10 years of experience. All the teachers 
reported they had no mental-health training during their undergraduate course work, and only one teacher reported having received any mental-health information since then.

When asked if the school district provided any mental-health services to students, eight responded that they did not know. Regarding their knowledge about district contact information for assistance with mental health, seven said they did not know whom to contact. Four stated that they knew whom to contact, but the responses were inconsistent. All 11 teachers reported that they did not know whom to contact in the community for assistance regarding mental health. In addition, prior to this study, none of the teachers were familiar with the proposed mental-health competencies.

\section{Data Collection}

In spring, 2016, an online questionnaire was used to collect demographic and background information of the participants. Although 11 participants completed the online questionnaire, only 10 teachers continued in the study and participated in the focus group and follow-up interviews. The data were coded indicating the school zone and number. This coding was consistently used to report findings.

Upon completion of the questionnaire, each participant received the article titled Developing a Comprehensive Curriculum Framework for Teacher Preparation in Expanded School Mental Health (Weston et al., 2008) to read two weeks prior to the focus group interview. The focus group interview at each school lasted approximately 60-90 minutes. These sessions were audio recorded, and then transcribed for analysis purposes. The protocol for the interview consisted of 10 questions prioritized by relevance to the three research questions.

Additionally, a single interview question was asked individually following the focus-group interview. Within a few days, each participant was contacted and asked if there was any other information they would like to contribute to the study. Each conversation was short, approximately 30 seconds to two minutes in length. Participant responses were recorded for data analysis.

\section{Data Analysis}

Using the research questions to guide the study, data were collected from general-education teachers from three elementary schools in one school district. Data included the online questionnaire responses, transcripts from the focus-group interviews, and the follow-up individual question. Triangulation of the three data sources supports validity of the data. All the data were analyzed using a reiterative process of reading, coding for themes, writing, and reflecting. Participants had the opportunity to read transcripts, as well as the findings for accuracy. Themes emerged for each of the three research questions.

\section{Findings}

For the first research question, three themes emerged. Participants indicated educators need greater knowledge on mental health, larger support systems, and self-care to be effective educators. Regarding the second research question, respondents generally supported the ideas of adopting the proposed educator mental-health competencies, but also had reservations, especially with implementation, which lent itself to two opposing themes. For the third question, the participants did not feel knowledgeable enough on the topic of mental health to provide comprehensive 
recommendations, but their overall indirect responses resulted in three themes. These include additions, adjustments, and major changes to the framework.

\section{Competencies Guide and Inform Participants' Practice}

The first research question examined how the mental-health competencies could inform and guide the teachers' practice. Participants concluded that educators who had knowledge and skills in the six targeted competencies (Weston et al., 2008) would be better equipped for today's classrooms. Three major themes represented their perspective: (a) need to be more knowledgeable in mental health; (b) need for support systems to assist in meeting the needs of their students with mental health challenges; and (c) need to include a competency on personal well-being for educators.

Educators need knowledge on mental health. All participants perceived knowledge on mental health as the foundation to guide and inform their classroom practice for their current student population. Most participants acknowledged their current lack of general knowledge about mental health, including: signs, symptoms, strategies, interventions, and resources. For example, TW2 said, "I would love to understand more about how their [students'] little minds work so I can figure out if he is being defiant or if he is overly stressed about something else in his life that I could help him with and also avoid the frustration of his defiance." She also stated that it would be beneficial to be further trained and educated on mental health. TE10 also supported the idea of mental-health training when she stated, "Teaching would be different with these competencies because I would be more knowledgeable and I would have had training and have resources to use." All three focus group interviews generated rich discussion about teaching and effective professional development for teachers. They believed that acquiring knowledge and skills in mental health through quality professional development would indeed guide and inform their teaching practice in a positive manner.

Educators want large and effective support systems. Participants perceived multiple support systems as a valuable way to both guide and inform a teachers' practice when working with students who have mental-health conditions. An extensive discussion regarding the fifth competency on multiple systems was geared toward support within their own school. Having additional support personnel would assist classroom teachers. TE10 said that if other people around the school were sharing the mental health responsibility, her job would be easier. Several teachers (TE9, TW1, TW2, TS7) stated that the school counselors should play a larger role in children's mental health. However, three of the participants (TS5, TW3, TE8) recognized that counselors are currently tasked to perform other duties. As an example, TW1 stated the guidance counselor in her school is good at talking with people but "she's wearing so many hats right now that she doesn't have a chance to do it." When asked about other support staff, for example the school psychologist and social worker, most of the teachers said they were not used to working with them, and some teachers (TW1, TS7, TE8) were unaware of those individuals in their respective school. All of the teachers from the east zone school said, no one at their school understood mental health. While discussing other support staff, TE8 suggested that a mental-health specialist be assigned to every school who could oversee helping others in the school building by providing resources, suggestions, strategies, and even assistance when speaking to family members. Overall, participants believed that a larger support network in and among the schools would be beneficial to teachers and their students. 
Besides support personnel in the schools, the participants also saw the inclusion of parent support as an important factor in effectively meeting the needs of the students. All teachers at the south-zone school were optimistic that the adoption of the competencies would lead to transparent and open discussions with the parents about the child's mental health. As TS5 noted, "if the teachers were more knowledgeable and skilled in mental health, parents would consider teachers to be credible on mental health, and partners in the solution". TS6 suggested that, "If we just had good background knowledge of where these kids have been and what has been going on in their life, it would really open our eyes to what we can do to help". All participants agreed that positive collaboration with the parents would lead to more effective support.

A third area of focus related to community support and resources in mental health to guide and inform teachers' instruction. The participating teachers spoke about the existence of MTSS in their school; a process for providing students' the help they needed to succeed. However, the teachers also stated MTSS is a lengthy, complex, and often uncertain process because teachers are asked to observe, collect data, and complete a lot of paperwork for students going through an MTSS process (TS6). Also, TW4 found that most MTSS referrals focused on academics first. Then, if there was a behavioral concern, teachers would start a new process for another behavioral MTSS process. To mitigate these problems, a teacher (TS7) at the south-zone school suggested a database of community resources be made available to all district employees upon the adoption of the mental-health competencies. She said, "I think that it would get them access to the help they need quicker and I think that's probably most important for these kids" (TS7). The participating teachers hoped that the adoption of these competencies would lead to larger support systems including all the stakeholders.

Educators support personal well-being. Most of the participants supported personal wellbeing, competency number six (Weston et al., 2008), as an important way to improve their teaching practice. TS5 noted that it is important for a teacher to be at his/her emotional best because the students notice when their teacher is burned out and stressed, and students' responses to that stress could range from empathy to chaos and out of control behavior. In addition, the high rate of teacher turnover nationwide might be connected to a lack of understanding of competency six, which outlines the need for teachers to demonstrate overall personal and professional well-being (TS5). At first, during the focus group with the teachers at the west-zone school, competency six was not mentioned as an important competency. When I brought it to the teachers' attention, TW1 said that "In a teacher's world, you would put them [children] before yourself." As the discussion unfolded, TW2 said, "Maybe six [competency] is higher than we really want to think it is because if it were higher maybe we could all last longer [as teachers]." However, TE9 thought it was a good idea to include competency six right from the start because the teacher's mental well-being is important. The teachers from the east-zone school also discussed the idea of having someone at the school with whom teachers can talk about their own mental-health issues. Teachers' personal well-being grew in importance throughout each focus group interview, and was ultimately perceived as a significant component of effective teaching.

\section{Participants' Reaction to Mandated Competencies}

The second research question asked how they would react if the competencies were adopted by the state. Adoption would mean that teachers would be expected to demonstrate competency in mental-health-related areas of education, which would necessitate new and different teacher training. For this question, two major themes emerged from the participants: (a) 
support for the adoption of the mental health competencies, and (b) concerns regarding the implementation of the competencies.

Support for the adoption of the mental-health competencies. All teacher participants agreed that mental-health care is relevant today and needed in the schools; therefore, they expressed their support related to the adoption of the proposed mental-health competencies. Participants believed that by adding the knowledge and skills associated with mental health to their preparation and training, they could become more effective classroom teachers. For example, TW2 shared a scenario illustrating her need for knowledge and skills on mental health. A year before she witnessed extreme bullying among the middle school students. Because of the bullying, she often worried about students who were bullied might attempt suicide. One day, a student inflicted selfharm by cutting herself in the girl's bathroom. The teacher acknowledged her ability to handle this kind of situation was limited to her own common sense and interpretation of best practices for these situations. She admitted that she could have done more for the students if she had known how to help, and ultimately, more learning could have taken place. Other stories were also shared in the focus group interviews about specific students with mental-health concerns. From all these stories, lack of knowledge, effective strategies, and resources emerged as common threads, which ultimately led to the conclusion that these competencies were essential for teachers.

Concerns with the implementation of the adopted mental-health competencies. Although there was support for the mental-health competencies, reluctance was also present due to teachers being overburdened and concerned about the implementation process. When asked how they would react to the adoption of these competencies, immediate reaction of the four teachers in the west-zone school indicated a feeling of already being overwhelmed with school-related responsibilities. In addition, the possibility of having to be responsible for one more aspect was just too much. TW2 responded, "Honestly, in all honesty, it [adoption of new competencies] would feel heavy because it would feel like there is already so much on my plate. It would be difficult to wrap my mind around such an enormous pile of information as well." Similarly, the teachers at the east-zone school also discussed feeling overburdened. For example, TE8 mentioned that certain students or cases could be complex and require a lot of time and resources which would be challenging. In a climate of overburdened teachers, the time to accomplish these new tasks seemed to cause concern regarding the adoption of these competencies.

In addition to feeling overburdened, the most reluctance to the adoption of the competencies emerged from concerns regarding the implementation process. Many participating teachers were skeptical about an effective implementation of the competencies due to past experiences with other district or school initiatives. Per TE10, at the beginning of each school year a new idea or program is presented with excitement, along with expectation of teachers' commitment to these new projects. However, very little additional training or support is provided, and gradually the new program dwindles away until it is non-existent. The following school year the cycle starts again with a new and different initiative. The other two participants from the eastzone school nodded in agreement. Lack of follow through and support for past implementation processes caused the participating teachers to share their concern regarding the implementation of these mental-health competencies if they were adopted statewide.

The quality and quantity of the necessary training needed to implement the mental-health competencies fully was a concern, as well. All the teachers discussed the need for quality training. The participants in both the west- and south-zone schools discussed how a credible presenter would be vitally important. As for quantity, all the participants described re-occurring sessions, which would be a "thread which runs through the year like a small nugget of information here and 
there (TW2)." The notion of effective training was emphasized through stories regarding teachers being continually asked to learn and utilize new programs without adequate training for successful implementation.

Implementation of the competencies would also require commitment and support. TE8 said that the teacher competencies would only work "if we had procedures set in place, if we had training set in place, and if we had people that we could identify who could help us if we didn't understand something or if we had mental health questions." Participants suggested that a strong infrastructure of support at both the district and school level would be important to have in place for implementing the educator competencies. Furthermore, one teacher believed the support had to start with the superintendent of schools. She stated, "I think our district has to be convinced that the problem is big enough for them to invest a lot of money and time into school-based mental health (TE8)." Unfortunately, the teacher participants were not confident about the reality of a strong infrastructure because it would take knowledge, time and money. Given the current practices in the district, receiving the needed support seemed unlikely, which caused feelings of reservations in all participants about the adoption of the proposed educator mental-health competencies.

\section{Participants' Recommendations about the Competencies}

This study not only investigated the participating teachers' perceptions on the mentalhealth competencies, but also examined teachers' recommendations regarding these competencies as the third research question. The participants agreed that the competencies were well developed. However, they did not feel knowledgeable enough on the topic of mental health to provide comprehensive recommendations. For example, TW3 stated, "I thought they [competencies] were pretty thorough", and it was a thought echoed by many of the participants without changes to recommend. In addition, TE8 noted, "I don't feel like I know enough about mental health to say that I would change anything." It was stated that teachers are not knowledgeable enough on the topic of mental health to determine whether these competencies should be changed. Although participants failed to give direct recommendations about the competencies, they implied suggestions in their comments throughout the focus group interviews. The participants' indirect comments regarding suggestions for the mental-health competencies are organized into three major themes: (a) additions to include in the competency framework; (b) small adjustments to the competencies; and (c) major changes to the entire format.

Additions to include in the competency framework. The participating teachers indicated two different additions to the current educator mental-health competencies: (a) a mandatory college course and (b) the inclusion of other school mental-health professionals. All 10 focusgroup participants agreed that students in the teacher preparation program would benefit from some instruction on mental health. The participants at the west-zone school suggested an additional course be included in teacher preparation programs. For example, TW1 found it beneficial to include a mandatory behavioral-health course in teacher preparation programs that would be in addition to the already existing classroom management course. TW2 considered it as a way to learn more about behavioral-health problems rather than avoiding the problem.

The mental-health competencies are written for educators. Although the participants recognized the need for teachers to become better informed, they also thought that other personnel in the school are needed in a similar capacity to meet the mental health demands of the student population effectively. The teachers wanted to have the competencies addressed and include all 
the other school-based personnel. For example, TE10 recalled a time working with a challenging student in which she felt, "it was just on me", and there was not a positive resolution for the specific situation. She said that the competencies should include other school personnel so everyone has a shared sense of responsibility. Several other teachers made similar comments throughout the focus group interviews (TE9, TW1, TS7) and wanted the competencies to add other professional roles, as well.

Adjustments to the competency framework. The participants suggested a reduction of content in two of the proposed competencies. Overall, their opinion was that laws and policies, along with data collection, were not the primary focus of a classroom teacher; therefore, the knowledge and skills associated with legal requirements could be reduced. On the other hand, the most important competencies should remain as they were formulated, specifically the ones associated to working with people; numbers two [learning supports], four [communication skills and relationship building], five [multiple systems], and six [personal and professional development and well-being]. The participating teachers wanted to adjust the first competency which is on key policies and laws that foster the delivery of effective and ethical learning supports and the third one about collecting and use of data (Weston et al., 2008). "Competencies one and three are lower on our list", stated TW1.

Major changes related to the competency framework. The participating teachers would change the format of the proposed mental-health competencies in two ways: (a) using simple language and (b) providing practical strategies. Although all teachers thought that the proposed competencies were well developed, the teachers from the south-zone school stated that the competencies were written at a high level of language complexity. TS7 noted that "the easier it is for people to understand on all different IQ levels, the easier it will be to get the buy-in that you need to help the kids." Her colleagues agreed and suggested to keep the competencies simple and to illustrate with examples. Besides using simple and clear language, the teachers also asked for practical solutions for mental-health challenges.

Participants suggested explicit instruction on practical strategies rather than a curriculum framework. Regarding the competencies that require that teachers identify, describe, and implement behavior management strategies, the teacher participants wanted to know specific strategies for solving the problems they are currently facing. For example, TS5 asked for "some effective strategies" during our conversation. The teachers at the east-zone school wished for a specific set of guidelines regarding behavior and consequences. In addition, TE10 strongly recommended having a resource guide listing consequences for every behavior. In support of the idea, TE9 added, "We need strategies to be able to pull out of our bag." Furthermore, TE10 also wanted explicit instruction regarding the effectiveness of commonly used consequences for working with students who have mental-health challenges, for example sending a student to the office, having a student change his/her color, or writing a note home. Another request was for direction on how to avoid triggers and effectively de-escalate students in crisis or in the throes of an outburst. For example, TS5 taught fifth grade and TS7 taught kindergarten, yet both teachers were concerned about out-of-control student behavior and the lack of effective strategies to address them. The teachers from the west-zone school had similar concerns and suggestions when discussing their behavior concerns. Specifically, TW4 wanted more information on atypical behavior and on common symptoms. TW2 thought a simple checklist could help with identifying signs and symptoms. The participants were interested in the acquiring knowledge and skills associated with mental health; however, they suggested changing the competencies to practical strategies written in simple, clear language. 


\section{Discussion and Implications}

The purpose of this study was to examine teachers' perspectives regarding educator mental health competencies. The findings showed that the participants see a great need in educators becoming more aware and competent of mental health conditions, and desire effective training using the proposed competencies. However, the overarching implication is that Educational leaders need to support ESMH and build capacity to address student mental-health concerns. Educational administrators should develop a culture and climate that includes open-mindedness, innovative thinking, and empathy regarding solutions to the mental-health challenges of today. Increasing awareness and education of mental-health conditions reduces stigma and allows for mental-health challenges to be assessed and addressed more effectively. Teachers are interested in being part of the solution. The specific findings in this study are supported by other international research studies and have practical implications. The implications are consolidated into four major areas.

\section{Pre-and In-Service Teacher Training}

Teachers can significantly impact the development and well-being of students, and the role of the teacher often extends beyond typical expectations (Anderson-Butcher, 2006; Meldrum et al., 2009; Paternite \& Johnston, 2005; Weyns et al., 2017). Therefore, it is important to consider a teacher's role in the expanded version of school mental health. Teachers reported a considerable need for mental-health support in school; however, they also recognized their own lack of knowledge and ill-preparedness to take on a role in mental health (Graham et al., 2011; Mazzer \& Rickwood, 2014; Rothi et al., 2008; Walter et al., 2006; Williams et al., 2007). Therefore, there is a critical need for teacher training in terms of preparing teachers with the knowledge and skills required to recognize signs and intervene appropriately in situations in which mental health may be a concern (Meldrum et al., 2009). Pre- and in-service mental-health training has begun in a limited way. Australia and Canada have recent initiatives in this area without the use of a competency based framework. To address the limited, and often fragmented, mental-health standards for teachers across the United States (Ball et al., 2016), a comprehensive framework of mental-health competencies for teachers was developed and proposed by Weston et al. (2008). The findings in this study support the use of these competencies to develop both pre-and in-service teacher training.

Developing and implementing the training are critical factors to consider when examining the effectiveness of any training. Thoughtful consideration to the adult learning theory (Knowles, 1984), which provided four basic principles is recommended at the developing stage. The participants should be involved in the planning and evaluation of their instruction. Their own experiences should provide the basis for their learning activities. The training should have immediate relevance and impact to their personal or professional life while helping to solve a problem.

Implementation of new practices and programs is complex, and many factors contribute to the effectiveness and sustainability of them. In accordance with the findings of a relevant study, Han and Weiss (2005) first addressed factors of the broader school system, including: alignment of institutional policy, the program's objectives, and allocation of resources. Next, they provided six factors of the teacher and school, which either facilitate or impede teachers' efforts and 
motivation to implement a program: (a) support of the program from the school principal, (b) teachers' self-efficacy beliefs, (c) professional burnout, (d) teachers' beliefs about the acceptability of the program, (e) the compatibility of the program with their own beliefs about student behavior, and (f) the anticipated effectiveness of the program. Finally, two program-specific factors were reviewed: teacher training and performance feedback. Clearly, implementation matters and a thoughtful strategy to address each of these factors is warranted prior to offering any training.

\section{Collaboration}

Teachers want and need multiple support systems, which include the school faculty, parents, and the community when working with students who have mental-health challenges. As shown in research, schools did not have the resources for addressing student emotional/behavioral challenges and the mental-health professionals were often too busy with unrelated tasks, rather than assisting with emotional/behavioral challenges (Weist et al., 2014). Organizational changes such as the number of mental-health professionals assigned to a school, and innovative ways those professionals are utilized needs serious consideration (Shernoff et al., 2016). The school mentalhealth professionals and teachers often fail to work collaboratively (Phillippo \& Kelly, 2014), which may limit their effectiveness. One way to encourage and support collaboration among school personnel is to create a table documenting each professional's competencies and indicate where they complement, hinder, and overlap with each other. Looking at all the competencies together may help in understanding each role and planning for collaboration.

Working with families and community partners is also important in building large systems of support. Establishing authentic partnerships to meet the demands of the students is a critical and necessary ongoing task. Teachers have been found to play a critical role in promoting family involvement (McDaniel, Schiele, Taylor, Haak, \& Weist, 2014). Participants in this study suggested that mental-health training for families could be offered on the school campus and that greater open dialogue among all stakeholders is necessary. Ultimately, accessing the appropriate assessment and treatment for the child is the main goal and involving families in mental-health services is important for positive outcomes (Hoagwood et al., 2010; McDaniel et al., 2014). Anderson-Butcher (2006) supported the idea that teachers can serve as an important link between students with a mental-health condition and the professional help. She also stated that mentalhealth professionals are better trained to handle the mental-health issues. Once a student's needs are identified, strategic supports and services must be in place within the school system and in the community (Adelman \& Taylor, 2010). Ultimately, collaboration between school personnel and community mental-health professionals is a significant component of ESMH (Weist et al., 2012). Establishing true partnerships between school and mental-health community organizations/offices would create a much needed support system helping to ensure students receive appropriate care.

\section{Well-Being}

Including teachers' professional and personal well-being as part of the competency framework is necessary and should be reinforced in all pre-and in-service mental-health training. Greenglass and Burke (2003) found that with occupational stress in teachers, the most frequently mentioned stressor is students' emotional and behavioral problems. In addition, Ekornes (2017) suggested that teacher stress, regarding mental health, is mainly the result of a mismatch between perceived demands and the perceived ability to cope with them. Teachers' well-being is 
foundational to all that is expected of them. When their well-being is compromised, so are students' academic gains, behavioral actions, and social-emotional development. In addition, when teachers leave the field due to professional stress and burnout, it impacts the educational profession. Ball and colleagues (2016) found that current state standards documents and InTASC national standards show an absence of the teacher well-being competency, educational leaders should recognize the importance of it and be intentional in including well-being as a priority for their faculty. This could include offering activities such as yoga, book clubs, and walking groups to school employees, as well as, providing on-site individual support and educational awareness workshops on related self-care topics.

\section{Closing the Researcher/Practitioner Gap}

Tension has existed between the education academics who produce research knowledge and the teachers who produce experiential knowledge, which is generally less valued. As shown in studies, practitioners wanted the research to be relevant, certain, and simple (Gore \& Gitlin, 2004; Gray, Ilse, \& Watson, 2011). Because academics write for other academics, the writing style failed to fulfill the desires of the practitioners. Therefore, teachers did not value the research and chose to rely more on trusted colleagues with experience (Gore \& Gitlin, 2004). Those findings support an academic-teacher divide, which creates a gap in what is known and done in the education profession. Bridging the gap between the academic educators and teachers is an important factor in addressing such a critical problem including the children's mental-health crisis. ESMH researchers should consider writing material specifically for teachers and purposely publish their articles in teacher-friendly journals that are easily accessible. The use of social media and popular websites are possible outlets for disseminating valuable information regarding ESMH topics. There is a large audience of teachers looking for information, strategies, and support regarding mental health. Targeting that audience may make the most difference for children, schools, and ultimately society.

\section{Conclusions}

World-wide, millions of students come to school each day struggling with a mental-health condition. Many of these students do not receive any professional services or treatment, other than what they receive at school. Although schools may have some mental-health professionals on staff, teachers have daily contact with the students. Teachers in several countries, including the U.S., have said they are unprepared to work with students who have emotional or behavioral problems, and they witness the various ways in which mental-health disorders impede student learning and personal well-being. Therefore, all teachers need training and support to increase their competency level for working with students who have mental-health disorders.

Through this study, findings have shown that teachers perceived the proposed educator mental-health competency curriculum framework (Weston et al., 2008) as useful and effective for developing teacher preparation and teacher professional development training. Additionally, all training needs to be high quality and delivered appropriately. Furthermore, the implementation of any school mental-health program needs to be carefully considered. Moreover, competency number six on personal well-being is of utmost importance. As found in this study, educational leaders and teachers must recognize the importance of their own well-being and take necessary action to maintain a balanced and positive state of mind so that they can best assist the students. 
If the need for ESMH practices goes unmet, children will continue to suffer emotionally, and barriers to learning will remain unsurpassed obstacles. All of which can lead to other school problems including discipline issues, poor attendance rates, higher dropout rates, and lower test performance scores. In addition, these unmet needs can ultimately contribute to large-scale societal problems such as substance abuse, large disability rates, overcrowded prisons, homelessness, and suicide. For these reasons, it is imperative for research on ESMH practices to facilitate the necessary changes in our schools and be easily accessible to school practitioners.

\section{Disclosure statement}

No potential conflict of interest was reported by the authors.

\section{Funding}

This research received no specific grant from any funding agency in the public, commercial, or non-profit sectors.

\section{References}

Adelman, H. S., \& Taylor, L. (2010). Mental health in schools: Engaging learners, preventing problems, and improving schools. Thousand Oaks, CA: Corwin.

Anderson-Butcher, D. (2006). The role of the educator in early identification, referral, and linkage. In R. Waller (Ed.), Fostering child \& adolescent mental health in the classroom (pp. 257274). Thousand Oaks, CA: Sage Publications. doi:10.4135/9781452232355.n15

Arslan, S. \& Yiğit, M. F. (2016). Investigation of the Impact of Emotional Intelligence Efficacy on Teachers' Multicultural Attitudes. Journal of Education and Practice, 7(11), 147-157.

Ball, A., Iachini, A. L., Bohnenkamp, J. H., Togno, N. M., Brown, E. L., Hoffman, J. A., \& George, M. W. (2016). School mental health content in state in-service K-12 teaching standards in the United States. Teaching and Teacher Education, 60, 312-320. doi:10.1016/j.tate.2016.08.020

Bishop, D. C., Giles, S. M., \& Bryant, K. S. (2005). Teacher receptiveness toward web-based training and support. Teaching and Teacher Education, 21(1), 3-14. doi:10.1016/j.tate.2004.11.002

Bradshaw, C. P., Bottiani, J. H., Osher, D., \& Sugai, G. (2014). The integration of positive behavioral interventions and supports and social and emotional learning. In M. Weist, N. Lever, C. Bradshaw, \& J. Owens (Eds.), Handbook of school mental health (pp. 101- 118). New York, NY: Springer.

Cammack, N. L., Brandt, N. E., Slade, E., Lever, N. A., \& Stephan, S. (2014). Funding expanded school mental health programs. In M. Weist, N. Lever, C. Bradshaw, \& J. Owens (Eds.), Handbook of school mental health (pp. 17-30). New York, NY: Springer.

Carothers, D. \& Parfitt, C. (2017). Disability or Language Difference: How Do We Decide? American Journal of Qualitative Research, 1(1), 1-12.

Climie, E. A. (2015). Canadian children's mental health building capacity in school-based intervention. Intervention in School and Clinic, 51(2), 122-125.

Creswell, J.W. (2013). Qualitative inquiry \& research design: Choosing among five approaches ( $3^{\text {rd }}$ ed.). Los Angeles, CA: Sage Publications. 
Deniz, M., \& Ersoy, E. (2016). Examining the Relationship of Social Skills, Problem Solving and Bullying in Adolescents. International Online Journal of Educational Sciences, 8(1), 1 -7.

Ekornes, S. (2017). Teacher stress related to student mental health promotion: The match between perceived demands and competence to help students with mental health problems. Scandinavian Journal of Educational Research, 61(3), 333-353. doi:10.1080/00313831.2016.1147068

Elias, M. J., Zins J. E., Graczyk, P. A., \& Weissberg, R. P. (2003). Implementation, sustainability, and scaling up of social-emotional and academic innovations in public schools. School Psychology Review, 32(3), 303-319.

Ersoy, E. (2015). Assessment of Adolescent Perceptions on Parental Attitudes on Different Variables. Journal of Education and Training Studies, 3(5), 165-176.

Ersoy, E., \& Ugur, H. (2015). The Relationship between Students' Self-esteem and Parental Attitudes in Turkish Society. The Anthropologist, 21(1-2), 112-119.

Ersoy, E., \& Deniz, M. E. (2016). Psychometric Properties of the Gifted Students' Coping with Anger and Decision Making Skills Scale. Journal of Education and Practice, 7(15), 121128.

Franklin, C. G. S., Kim, J. S., Ryan, T. N., Kelly, M. S., \& Montgomery, K. L. (2012). Teacher involvement in school mental health interventions: A systematic review. Children and Youth Services Review, 34(5), 973-982. doi:10.1016/j.childyouth.2012.01.027

Gray, D. E., Ilse, P., \& Watson, S. (2011). Spanning the HRD academic-practitioner divide: Bridging the gap through mode 2 research. Journal of European Industrial Training, 35(3), 247-263. doi:10.1108/03090591111120403

Gore, J. M. \& Gitlin, A. D. (2004). [RE]visioning the academic-teacher divide: Power and knowledge in the educational community. Teachers and Teaching, 10(1), 35-58. doi:10.1080/13540600320000170918

Graham, A., Phelps, R., Maddison, C., \& Fitzgerald, R. (2011). Supporting children's mental health in schools: Teacher views. Teachers and Teaching: Theory and Practice, 17(4), 479-496.

Greenglass, E. R., \& Burke, R. J. (2003). Teacher Stress. In M. F. Dollard, A. H. Winefield, \& H. Winefield (Eds.), Occupational Stress in the Service Professions (pp. 213-236). London: Taylor \& Francis. doi:10.1201/9780203422809.ch8

Han, S. S., \& Weiss B. (2005). Sustainability of teacher implementation of school-based mental health programs. Journal of Abnormal Child Psychology, 33(6), 665-679. doi:10.1007/s10802-005-7646-2

Brooks, J. G. (1999, December 30). In search of understanding: The case for constructivist classrooms. [Review of the book, by C. Halpern]. American Journal of Qualitative Research, 1(1), 32-36.

Hoagwood, K. E., Cavaleri, M. A., Olin, S. S., Burns, B. J., Slaton, E., Gruttadaro, D. \& Hughes, R. (2010). Family support in children's mental health: A review and synthesis. Clinical Child and Family Psychology Review, 13(1), 1-45.

Jorm, A. F., Kitchener, B. A., Sawyer, M. G., Scales, H., \& Cvetkovski, S. (2010). Mental health first aid training for high school teachers: A cluster randomized trial. BMC Psychiatry, 10(51). doi:10.1186/1471-244X-10-51

Knowles, M. S. (1984). Andragogy in action: Applying modern principles of adult learning. San Francisco, CA: Jossey-Bass. 
Koller, J. R., Osterlind, S., Paris, K., \& Weston, K. J. (2004). Differences between novice and expert teachers' undergraduate preparation and ratings of importance in the area of children's mental health. International Journal of Mental Health Promotion, 6(2), 40-45.

Lafee, S. (2013). The school's role in students' mental health. School Administrator, 7(70), 24-30.

Mazzer, K. R. \& Rickwood, D. J. (2014). Teachers' role breadth and perceived efficacy in supporting student mental health. Advances in School Mental Health Promotion, 8(1), 2941. doi:10.1080/1754730X.2014.978119

McDaniel, H. L., Schiele, B. E., Taylor, L. K., Haak, J., \& Weist, M. D. (2014). Strengthening components and processes of family involvement in school mental health. In M. Weist, N. Lever, C. Bradshaw, \& J. Owens (Eds.), Handbook of school mental health (pp. 195-207). New York, NY: Springer. doi:10.1007/978-1-4614-7624-5_15

McGorry, P., Bates, T., \& Birchwood, M. (2013). Designing youth mental health services for the 21st century: Examples from Australia, Ireland and the UK. The British Journal of Psychiatry, 202(54), 30-35. doi:10.1192/bjp.bp.112.119214

Meldrum, L., Venn, D., \& Kutcher, S. (2009). Mental health in schools: How teachers have the power to make a difference. Health \& Learning Magazine, 8, 3-5.

National Center for Educational Statistics. (2014). Fast Facts. Washington, DC: Author. Retrieved from http://nces.ed.gov/fastfacts/display.asp?id=372

National Research Council and Institute of Medicine. (2009). Preventing mental, emotional, and behavioral disorders among young people: Progress and possibilities. M.E. O'Connell, T. Boat, \& K.E. Warner (Eds.), Board of Children, Youth, and Families, Division of Behavioral and Social Sciences and Education. Washington, DC: The National Academies Press.

Nellis, L. M. (2012). Maximizing the effectiveness of building teams in response to intervention implementation. Psychology in the Schools, 49(3), 245-256. doi:10.1002/pits.21594

New Freedom Commission on Mental Health. (2003). Achieving the promise: Transforming mental health care in America final report (DHHS Pub. No. SMA-03-3832). Rockville, MD: U.S. Department of Health and Human Services.

O'Connell, M. E., Boat, T., \& Warner, K. E. (2009). Preventing mental, emotional, and behavioral disorders among young people: Progress and possibilities. Washington, DC: Committee on the Prevention of Mental Disorders and Substance Abuse Among Children, Youth, and Young Adults: Research Advances and Promising Interventions; Institute of Medicine; National Research Council, The National Academies Press.

Paternite, C. E., \& Johnston, T. C. (2005). Rationale and strategies for central involvement of educators in effective school-based mental health programs. Journal of Youth and Adolescence, 14(1), 41-49. doi:10.1007/s10964-005-1335-x

Phillippo, K. L. \& Kelly, M. S. (2014). On the fault line: A qualitative exploration of high school teachers' involvement with student mental health issues. School Mental Health, 6(3). doi:10.1007/s12310-013-9113-5

Rossen, E., \& Cowan, K.C. (2014). Improving mental health in schools. Phi Delta Kappan, 96(4), 8-13. doi:10.1177/0031721714561438

Rothi, D. M., Leavey, G., \& Best, R. (2008). On the front-line: Teachers as active observers of pupils' mental health. Teaching and Teacher Education, 24(5), 1217-1231. doi:10.1016/j.tate.2007.09.011 
Mental health competencies

Sawyer, M. G., Arney, F. M., Baghurst, P. A., Clark, J. J., Graetz, B. W., Kosky, R. J., Nurcombe, B., Patton, G. C., Prior, M. R., Raphael, B., Rey, J. M., Whaites, L. C., \& Zubrick, S. R. (2001). The mental health of young people in Australia: key findings from the child and adolescent component of the national survey of mental health and well-being. Australian and New Zealand Journal of Psychiatry, 35(6), 806-814. doi:10.1046/j.14401614.2001.00964.x

Schonert-Reichl, K. A. (2017). Social and emotional learning and teachers. The Future of Children, 27(1), 137-155.

Shernoff, E.S., Frazier, S.L., Marinez-Lora, A.M., Lakind, D., Atkins, M.S., Jakobsons, L., Hamre, B.K., Bhaumik, D.K., Parker-Katz, M., Neal, J.W., Smylie, M.A., \& Patel, D.A. (2016). Expanding the role of school psychologists to support early career teachers: A mixedmethod study. School Psychology Review, 45(2), 226-249. doi:10.17105/SPR45-2.226-249

Stake, R.E. (1995). The art of case study research. Thousand Oaks, CA: Sage Publications.

Volk, A. A., Craig, W., Boyce, W., \& King, M. (2006). Perceptions of parents, mental health, and school amongst Canadian adolescents from the provinces and the northern territories. Canadian Journal of School Psychology, 21(1-2), 33-46.

Walter, H. J., Gouze, K., \& Lim, K. G. (2006). Teachers' beliefs about mental health needs in inner city elementary schools. Journal of the American Academy of Child and Adolescent Psychiatry, 45(1), 61-68.

Waxman, R. P., Weist, M. D., \& Benson, D. M. (1999). Toward collaboration in the growing education-mental health interface. Clinical Psychology Review, 19(2), 239-253. doi:10.1016/S0272-7358(98)00072-5

Weist, M. D., \& Evans, S. W. (2005). Expanded school mental health: Challenges and opportunities in an emerging field. Journal of Youth and Adolescence, 34(1), 3-6. doi:10.1007/s10964-005-1330-2

Weist, M. D., Lever, N. A., Bradshaw, C. P., \& Owens, J. S. (2014). Further advancing the field of school mental health. In M. Weist, N. Lever, C. Bradshaw, \& J. Owens (Eds.), Handbook of school mental health (pp. 1-14). New York, NY: Springer. doi:10.1007/978-1-4614-76245_1

Weist, M. D., Mellin, E. A., Chambers, K. L., Lever, N. A., Haber, D., \& Blaber, C. (2012). Challenges to collaboration in school mental health and strategies for overcoming them. Journal of School Mental Health, 82(2), 97-105. doi:10.1111/j.1746-1561.2011.00672.x

Weston, K. J., Anderson-Butcher, D., \& Burke, R. W. (2008). Developing a comprehensive curriculum framework for teacher preparation in expanded school mental health. Advances in School Mental Health Promotion, 1(4), 25-36. doi:10.1080/1754730X.2008.9715737

Weyns, T., Verschueren, K., Leflot, G., Onghena, P., Wouters, S., \& Colpin, H. (2017). The role of teacher behavior in children's relational aggression development: A five-wave longitudinal study. Journal of School Psychology, 64, 17-27. doi:10.1016/j.jsp.2017.04.008

Whitley, J., Smith, J. D., \& Vaillancourt, T. (2012). Promoting mental health literacy among educators: Critical in school-based prevention and intervention. Canadian Journal of School Psychology, 28(1), 56-70. doi:10.1177/0829573512468852

Williams, J. H., Horvath, V. E., Wei, H., Van Dorn, R. A., \& Jonson-Reid, M. (2007). Teacher's perspectives of children's mental health service needs in urban elementary schools. Children \& Schools, 29(2), 95-107. 
Mental health competencies

World Health Organization. (2003). Investing in mental health [Report]. Geneva, Switzerland: Author. Retrieved from www.who.int/mental_health/en/investing_in_mnh_final.pdf

Yigit, I. H., \& Tatch, A. (2017). Syrian refugees and Americans: Perceptions, attitudes and insights. American Journal of Qualitative Research, 1(1), 13-31.

Manuscript received February 27, 2018

Final revision received March 24, 2018

Accepted April 02, 2018

Dr. Diane Kratt is an instructor in the College of Education at Florida Gulf Coast University. 10501 FGCU Blvd. South, Fort Myers, FL 33965; E-mail: dkratt@fgcu.edu. After teaching in the K-12 setting for 20 years, Diane began her work in teacher preparation. Her primary role in the college is as a coordinator for clinical experiences. Additionally, Diane has been a mental health advocate for over 15 years and now combines these interests in her role as an instructor and as her research agenda on school-based mental health. 